\title{
PENINGKATAN KEMANDIRIAN MAHASISWA PENDIDIKAN FISIKA PADA MATA KULIAH MEKANIKA MELALUI METODE RECIPROCAL TEACHING
}

\author{
Fajar Fitri \\ Program Studi Pendidikan Fisika, Fakultas Keguruan dan Ilmu Pendidikan, \\ Universitas Ahmad Dahlan \\ Email: fajarfitri@gmail.com
}

\begin{abstract}
Abstrak
Penelitian ini bertujuan untuk mendeskripsikan kemandirian mahasiswa setelah mengikuti perkuliahan dengan Reciprocal Teaching. Subjek penelitian ini adalah mahasiswa Program Studi Pendidikan Fisika UAD yang sedang menempuh mata kuliah Mekanika pada tahun ajaran 2015/2016.Penelitian tindakan kelas meliputi tahap perencanaan, tahap pelaksanaan, dan tahap refleksi.Kegiatan tersebut berulang selama dua siklus. Hasil penelitian menunjukkan bahwa setelah mengikuti perkuliahan dengan pendekatan Reciprocal Teaching, 80,3\% mahasiswa telah mengalami kemandirian belajar baik secara individual maupun klasikal.
\end{abstract}

Kata Kunci: reciprocal teaching, kemandirian mahasiswa

\begin{abstract}
This research aims to describe thestudent independence after follow the Reciprocal Teaching of Learning. The subjects of this research are students in study program of physics education Ahmad Dahlan University who are studying Mechanics at school year of 2015/2016. Classroom Action Research consists of plan, do, and reflection. This activity repeated two cycles. The result is after follow the Reciprocal Teaching of Learning 80,3\% students reached good individual and classical independence.
\end{abstract}

Keywords: reciprocal teaching, student independence

\section{PENDAHULUAN}

Mekanika merupakan salah satu mata kuliah yang penting dan mendasar dalam fisika dan harus dikuasai oleh mahasiswa calon guru fisika.Untuk mencapai tujuan tersebut, maka diperlukan adanya sarana pendukung, pemilihan metode, pendekatan pembelajaran yang sesuai, dan suasana kondusif yang melibatkan mahasiswa aktif dalam kegiatan pembelajaran. 
Fajar Fitri -Peningkatan Kemandirian Mahasiswa...

Dalam perkuliahan mekanika, mahasiswa pendidikan Fisika belum mencapai kemampuan-kemampuan yang seharusnya dicapai dalam perkuliahan. Mahasiswa belum memahami materi Mekanika dengan baik. Di samping itu, aspek kemandirian belajar mahasiswa belum tumbuh dengan optimal. Indikator yang menunjukkan hal tersebut adalah mahasiswa masih mengalami kesulitan ketika diminta untuk menjelaskan suatu konsep yang terdapat pada buku ajar. Indikator lainnya adalah ketika mahasiswa diminta mengerjakan Pekerjaan Rumah (PR) mahasiswa belum mengerjakan secara maksimal, belum berusaha mendiskusikannya bersama teman, atau mencari referensi yang relevan. Pada saat perkuliahan pun keterlibatan mahasiswa secara umum masih pasif.

Faktor yang menyebabkan kondisi di atas diantaranya adalah pelaksanaan pembelajaran yang belum melibatkan mahasiswa secara aktif. Oleh karena itu diperlukan perbaikan proses pembelajaran dengan cara menerapkan pendekatan pembelajaran relevan yang dapat menumbuhkan kemandirian belajar mahasiswa. Salah satu pendekatan yang diharapkan dapat meningkatkan kemandirian mahasiswa adalah pendekatan Reciprocal Teaching. Reciprocal Teaching adalah suatu prosedur pengajaran atau pendekatan pengajaran yang dirancang untuk mengerjakan mahasiswa tentang strategi-strategi kognitif serta untuk membantu mahasiswa memahami materi perkuliahan dengan baik (Doolittle, E. P. Et. Al., 2006: 106; Arends, 1997: 266).

Dalam pendekatan reciprocal teaching, diajarkan beberapa strategi pemahaman mandiri seperti meringkas atau merangkum, membuat pertanyaan, dan menjelaskan atau mem-presentasikan. Mahasiswa diberi tugas untuk mempelajari satu topik selanjutnya mahasiswa memahami inti topik tersebut, memberikan contoh soal dan penyelesaian, kemudian mempresentasikannya di depan kelas.

\section{METODE}

Penelitian ini merupakan penelitian tindakan kelas dengan dua siklus dilaksanakan di Program Studi 
Fajar Fitri -Peningkatan Kemandirian Mahasiswa...

Pendidikan Fisika UAD selama bulan September 2015 hingga Desember 2015. Subjek penelitian adalah mahasiswa Program Studi Pendidikan Fisika Semester tiga yang sedang menempuh mata kuliah Mekanika pada tahun akademik 2015/2016.Subjek penelitian ini berjumlah 24 orang mahasiswa.

Prosedur penelitian terdiri atas tiga tahap yaitu tahap perencanaan, tahap pelaksanaan (tindakan dan observasi), dan tahap refleksi.Penelitian Tindakan Kelas yang dilakukan pada penelitian ini terdiri atas dua siklus.

1. Siklus I

a. Tahap perencanaan

Pada tahap ini yang dilakukan peneliti adalah mempersiapkan perangkat pembelajaran, instrumen penelitian, dan langkahlangkah pembelajaran reciprocal teaching. Dosen terlebih dahulu menjelaskan kepada mahasiswa tentang rencana perkuliahan selama satu semester terutama mengenai persiapan mahasiswa dalam melakukan pembelajaran dengan pendekatan

reciprocal

teaching.

b. Tahap pelaksanaan

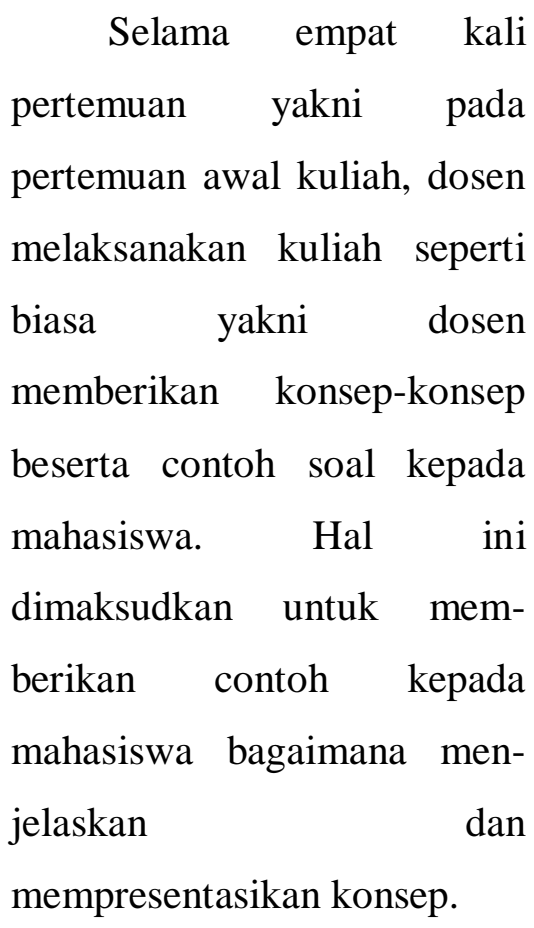

Pada

pertemuan

selanjut-nya, dosen

membentuk kelompok mahasiswa di mana setiap kelompok beranggotakan lima orang. Setiap kelompok diberi tugas untuk mempelajari materi perkuliahan pada topik tertentu, membuat rangkuman, dan membuat contoh soal beserta penyelesaiannya. Setiap pertemuan ada dua hingga tiga kelompok yang maju ke depan kelas untuk 
Fajar Fitri -Peningkatan Kemandirian Mahasiswa...

mempresentasikan konsep

yang telah didiskusikan.

Selama kegiatan

perkuliahan, dilakukan

observasi untuk mengamati

proses pembelajaran dan

menilai presentasi mahasiswa.

Di samping itu, mahasiswa

diberikan angket yang dapat

mengukur kemandirian belajar

mahasiswa.

c. Tahap refleksi

Setelah tujuh kali pertemuan perkuliahan

Mekanika, dilaksanakan ujian

sisipan I. Berdasarkan hasil

ujian sisipan I, hasil observasi, dan hasil diskusi dengan mahasiswa maka dilakukan refleksi.Hasil refleksi pada siklus I kemudian dimanfaatkan dalam penyusunan rencana tindakan pada siklus kedua.

2. Siklus II

a. Tahap perencanaan

Pada tahap ini peneliti mempersiapkan perangkat pembelajaran, instrumen penelitian, dan langkah-langkah pembelajaran dengan mem- pertimbangkan hasil dari refleksi pada siklus I.

b. Tahap pelaksanaan

Seperti pada siklus pertama, pada tahap pelaksanaan siklus kedua mahasiswa

mempresentasikan konsep yang telah didiskusikan dalam kelompoknya.

Observasi dilakukan selama proses perkuliahan, sedangkan angket kemandirian belajar mahasiswa diberikan setelah semua kelompok maju ke depan kelas.

c. Tahap refleksi

Setelah empat belas kali pertemuan perkuliahan Mekanika, dilakukan ujian sisipan II. Berdasarkan hasil ujian sisipan II, hasil observasi, dan hasil diskusi dengan mahasiswa selanjutnya di-lakukan refleksi.

Untuk memperoleh data penelitian digunakan dua perangkat pembelajaran yakni SAP (Satuan 
Fajar Fitri -Peningkatan Kemandirian Mahasiswa...

Acara Perkuliahan) yang berisi identitas mata kuliah, tujuan mata kuliah, deskripsi mata kuliah, metode penilaian, buku acuan, dan jabaran topik pada setiap pertemuan, kompetensi dasar, materi pokok, sub materi pokok, dan langkah-langkah pembelajaran secara umum.

Disamping itu berupa buku ajar yang berisi uraian materi dan contoh soal beserta penyelesaiannya.

Instrumen penelitian terdiri atas lembar observasi proses pembelajaran, lembar penilaian presentasi mahasiswa, angket kemandirian belajar, dan tes prestasi belajar.

1. Lembar observasi kegiatan pembelajaran

Lembar observasi kegiatan ini berupa catatan-catatan penting selama perkuliahan berlangsung.Adapun hasil dari lembar observasi ini dapat dijadikan sebagai sarana untuk melakukan refleksi.

2. Angket kemandirian belajar mahasiswa

Angket kemandirian belajar mahasiswa berisi pernyataanpernyataan yang digunakan untuk mengetahui kemandirian belajar mahasiswa pada saat melakukan perkuliahan dengan pendekatan reciprocal teaching.

3. Tes hasil belajar

Tes hasil belajar digunakan untuk mengetahui pemahaman konsep mahasiswa setelah mengikuti perkuliahan dengan pendekatan reciprocal teaching. Tes hasil belajar meliputi ujian sisipan I dan ujian sisipan II.

Setelah dilakukan observasi, pengisian angket oleh mahasiswa, dan ujian sisipan, maka data dianalisis secara kuantitatif dan kualitatif.Teknik kualitatif digunakan untuk menentukan keterlaksanaan rencana perkuliahan serta hambatanhambatan yang muncul dalam pelaksanaan perkuliahan.Adapun teknik kuantitatif digunakan untuk mengukur kemandirian belajar mahasiswa.

Dalam mendeskripsikan kemandirian belajar mahasiswa maka diberikan angket yang harus diisi oleh mahasiswa. Setiap pernyataan pada angket memiliki skor antara 1 sampai 5. Mahasiswa dikatakan memiliki 
Fajar Fitri -Peningkatan Kemandirian Mahasiswa...

kemandirian belajar yang baik ketika lebih dari $50 \%$ mahasiswa memiliki jumlah skor rata-rata lebih dari 2,5.

\section{HASIL DAN PEMBAHASAN}

Nilai

akhir

mahasiswa

ditentukan berdasarkan kontrak belajar dosen dan mahasiswa pada awal perkuliahan yakni berdasarkan nilai tugas, presensi, nilai ujian sisipan, dan ujian akhir. Berikut ini daftar nilai Mekanika Prodi Pendidikan Fisika.

Tabel 1. Daftar Nilai Mekanika Prodi Pendidikan Fisika

\begin{tabular}{|l|c|c|l|}
\hline \multirow{2}{*}{ No. Abs. } & \multicolumn{2}{|c|}{ Nilai akhir } & \multirow{2}{*}{ Keterangan } \\
\cline { 2 - 3 } & Angka & Huruf & \\
\hline 1. & 7.24 & B & Tuntas \\
\hline 2. & 7.63 & B & Tuntas \\
\hline 3. & 7.22 & B & Tuntas \\
\hline 4. & 8.42 & A & Tuntas \\
\hline 5. & 8.75 & A & Tuntas \\
\hline 6. & 7.82 & B & Tuntas \\
\hline 7. & 7.02 & B & Tuntas \\
\hline 8. & 7.39 & B & Tuntas \\
\hline 9. & 7.93 & B & Tuntas \\
\hline 10. & 7.74 & B & Tuntas \\
\hline 11. & 8.40 & A & Tuntas \\
\hline 12. & 8.23 & A & Tuntas \\
\hline 13. & 7.04 & B & Tuntas \\
\hline 14. & 7.83 & B & Tuntas \\
\hline 15. & 7.17 & B & Tuntas \\
\hline 16. & 8.70 & A & Tuntas \\
\hline 17. & 7.80 & B & Tuntas \\
\hline 18. & 7.59 & B & Tuntas \\
\hline 19. & 7.77 & B & Tuntas \\
\hline 20. & 7.51 & B & Tuntas \\
\hline 21. & 8.07 & A & Tuntas \\
\hline 22. & 8.25 & A & Tuntas \\
\hline 23. & 6.59 & B & Tuntas \\
\hline 24. & 6.64 & B & Tuntas \\
\hline
\end{tabular}

pembelajaran secara mandiri dan

Pada akhir siklus I ketuntasan berkelompok. Oleh karena itu pada belajar klasikal belum tercapai antara siklus II, mahasiswa diberikan motivasi lain disebabkan karena mahasiswa dan arahan-arahan yang lebih jelas belum terbiasa untuk aktif melakukan dalam melakukan pembelajaran dengan 
Fajar Fitri-Peningkatan Kemandirian Mahasiswa ...

pendekatan reciprocal teaching,

Rata-rata kemampuan presentasi misalnya dengan menyebutkan mahasiswa pada siklus I dan siklus II referensi yang sesuai, tips-tips adalah baik. Pada siklus I skor rata-rata mempresentasikan topik di depan yang dicapai mahasiswa adalah 2,9 dan kelas, dan memilih soal-soal. pada siklus II skor rata-rata yang Ketuntasan belajar dapat dicapai karena dicapai mahasiswa meningkat sebesar mahasiswa dapat berperan aktif dalam pembelajaran yakni dengan cara maksimal yang telah ditetapkan berdiskusi bersama teman sekelompok, sebelumnya yakni 2,5.

membuat paper dan slide presentasi, mencari referensi lain, mengerjakan beberapa contoh soal, dan sebagainya.

Di bawah ini adalah tabel ratarata kemandirian belajar mahasiswa pada siklus I dan siklus II.

Tabel 2. Hasil Kemandirian Belajar Mahasiswa pada Siklus I

\begin{tabular}{|c|c|c|c|c|c|}
\hline \multirow{2}{*}{ No } & \multicolumn{5}{|c|}{ Persentase kemandirian belajar (\%) } \\
\cline { 2 - 6 } & tdk pernah & Jarang & Kadang & Sering & Selalu \\
\cline { 2 - 6 } & I & I & I & I & I \\
\hline 1 & 0 & 16.6 & 12.5 & 41.6 & 29.1 \\
\hline 2 & 4.2 & 25 & 33.3 & 16.6 & 20.8 \\
\hline 3 & 4.2 & 8.3 & 37.5 & 41.6 & 8.3 \\
\hline 4 & 0 & 4.1 & 45.8 & 41.6 & 8.3 \\
\hline 5 & 4.2 & 20.8 & 41.6 & 16.6 & 16.6 \\
\hline 6 & 4.2 & 41.6 & 33.3 & 8.3 & 12.5 \\
\hline 7 & 0 & 4.1 & 20.8 & 33.3 & 41.6 \\
\hline 8 & 8.3 & 25 & 41.6 & 16.6 & 8.3 \\
\hline 9 & 0 & 4.1 & 33.3 & 50 & 12.5 \\
\hline 10 & 0 & 4.2 & 25 & 50 & 20.8 \\
\hline 11 & 4.2 & 25 & 37.5 & 20.83 & 12.5 \\
\hline 12 & 0 & 0 & 16.6 & 41.6 & 41.6 \\
\hline 13 & 8.3 & 16.6 & 41.6 & 20.8 & 12.5 \\
\hline 14 & 0 & 12.5 & 33.3 & 50 & 4.1 \\
\hline 15 & 0 & 8.3 & 16.6 & 50 & 25 \\
\hline Tot & 2.5 & 14.4 & 31.4 & 33.3 & 40 \\
\hline
\end{tabular}

Berdasarkan tabel di atas, pada siklus I kategori sering dan selalu sebanyak jumlah mahasiswa yang memilih $51,66 \%$ lebih besar daripada jumlah 
Fajar Fitri -Peningkatan Kemandirian Mahasiswa...

mahasiswa yang memilih kategori kadang-kadang, jarang, dan tidak pernah. Dengan demikian dapat disimpulkan bahwa mahasiswa memiliki kemandirian belajar yang baik, namun belum bisa dikatakan optimal karena masih ada 48,34\% mahasiswa yang belum memiliki kemandirian belajar.
Pada siklus II, seperti terdapat pada tabel 3, jumlah mahasiswa yang memilih kategori sering dan selalu sebanyak 80,28\%. Hal ini jauh lebih besar dibandingkan pada siklus I. Dengan demikian setelah melalui siklus II, kemandirian belajar mahasiswa sudah bisa dikatakan baik dan optimal.

Tabel 3. Hasil Kemandirian Belajar Mahasiswa pada Siklus II

\begin{tabular}{|c|l|l|l|l|l|}
\hline \multirow{2}{*}{ No } & \multicolumn{5}{|c|}{ Persentase kemandirian belajar (\%) } \\
\cline { 2 - 6 } & tidak pernah & Jarang & Kadang & Sering & Selalu \\
\cline { 2 - 6 } & & & & & II \\
\hline 1 & 0 & 4.1 & 16.6 & 25 & 54.1 \\
\hline 2 & 0 & 4.1 & 8.3 & 54.1 & 33.3 \\
\hline 3 & 0 & 8.3 & 4.1 & 62.5 & 25 \\
\hline 4 & 0 & 0 & 4.1 & 54.1 & 41.6 \\
\hline 5 & 0 & 4.1 & 8.3 & 37.5 & 50 \\
\hline 6 & 0 & 4.1 & 25 & 29.1 & 41.6 \\
\hline 7 & 0 & 0 & 12.5 & 45.8 & 41.6 \\
\hline 8 & 0 & 4.1 & 41.6 & 29.1 & 25 \\
\hline 9 & 0 & 0 & 20.8 & 20.8 & 58.3 \\
\hline 10 & 0 & 0 & 12.5 & 29.1 & 58.3 \\
\hline 11 & 0 & 0 & 8.3 & 41.6 & 50 \\
\hline 12 & 0 & 0 & 8.3 & 50 & 41.6 \\
\hline 13 & 0 & 8.3 & 41.6 & 33.3 & 16.6 \\
\hline 14 & 0 & 8.3 & 29.1 & 37.5 & 25 \\
\hline 15 & 0 & 0 & 8.3 & 50 & 41.6 \\
\hline tot & 0 & 3.0 & 16.6 & 40 & 40.3 \\
\hline
\end{tabular}

Pada siklus I, mahasiswa belum terbiasa untuk melakukan pembelajaran dengan pendekatan reciprocal teaching sehingga keaktifan mahasiswa seperti bertanya pada dosen, berdiskusi pada teman, mempersiapkan pelajaran secara individual, mencari reverensi dan lain-lain belum tampak secara optimal. Akan tetapi pada saat siklus 
Fajar Fitri -Peningkatan Kemandirian Mahasiswa...

II, mahasiswa sudah bisa mahasiswa Prodi Pendidikan Fisika menyesuaikan diri dengan pola pembelajaran yang dilakukan dalam perkuliahan yang menuntut siswa aktif belajar secara mandiri.

Kendala yang dihadapi pada saat perkuliahan diantaranya mahasiswa belum mampu mengalokasikan waktu dengan baik, sehingga banyak waktu yang habis untuk membahas soal-soal.Lamanya waktu yang diperlukan berakibat tidak terselesaikannya materi perkuliahan, sehingga hanya materimateri pokok saja yang disampaikan di dalam perkuliahan, sedangkan materi pengembangan belum berhasil dibahas. Hal lain yang kurang mendukung proses pelaksanaan reciprocal teaching adalah kurangnya referensi yang bisa dipinjam oleh mahasiswa di perpustakaan.

\section{KESIMPULAN}

Berdasarkan hasil penelitian, maka dapat disimpulkan sebagai berikut:

Setelah mengikuti perkuliahan dengan pendekatan reciprocal teaching, kemandirian belajar semester tiga Universitas Ahmad Dahlantahun ajaran 2015/2016 terkategori baik sebesar $80,3 \%$.

\section{SARAN}

Berdasarkan hasil penelitian, peneliti menyarankan agar para dosen dapat menerapkan pendekatan reciprocal teaching dalam melakukan perkuliahan.Pemilihan materi perlu dilakukan agar sesuai dengan tingkat kemampuan mahasiswa.Disamping itu perlu juga memperhatikan alokasi waktu agar tujuan perkuliahan dapat tercapai serta menyediakan berbagai fasilitas dan referensi yang memadai.

\section{DAFTAR PUSTAKA}

Doolittle, E. P., D. Hicks, C. F. Triplett, and W. D. Nicholas.2006. "Reciprocal Teaching for Reading Comprehension in Higher Education: A Strategy for Fostering the Deeper Understanding of Texts". International Journal of Teaching and Learning in Higher Education, Volume 17, (2), pp. 106-118.

Eli Rohaeti, dkk. 2011. "Peningkatan Prestasi dan Kemandirian Belajar Mahasiswa Melalui Pendekatan Reciprocal Teaching dan Cooperative 
Learning". Makalah Penelitian. Jurdik Kimia FMIPA UNY.

Ngalim Purwanto. 2002. PrinsipPrinsip dan Teknik Evaluasi Pengajaran. Bandung: PT Remaja Rosdakarya.

Riding Richard \& Rayner Stephen. 1998. Cognitive Styles and Learning Strategis. London: David Fulton.

Sardiman A. M. 2005. Interaksi dan Motivasi Belajar Mengajar. Jakarta: PT Raja Grafindo Persada.

Silberman, Melvin, L. 1996. Active Learning. Boston: Allyn and Bacon.

Supriyono Koes H. 2003. Strategi Pembelajaran Fisika. Malang: FMIPA Universitas Negeri Malang.

U.S. Department of Education. 2005. Helping Your Child Learn Science. Washington, D.C: ED Pubs. 